Departamento de Ciência e Tecnologia, Secretaria de Ciência, Tecnologia e Insumos Estratégicos, Ministério da Saúde

Correspondência | Correspondence: Decit - Departamento de Ciência e Tecnologia do Ministério da Saúde

Esplanada dos Ministérios

Bloco G sala 845

70058-900 Brasília, DF, Brasil

Texto de difusão técnico-científica do Ministério de Saúde.

\section{Utilização de conhecimentos científicos na gestão da saúde}

\section{Utilization of scientific knowledge in health management}

Os serviços, estabelecimentos e sistemas de saúde são estruturas organizacionais complexas. São organizações que têm objetivos múltiplos e, às vezes, ambíguos, que desenvolvem processos de trabalho sofisticados e diversos e que adotam vários mecanismos de alocação de recursos, nem sempre baseados na mesma lógica. Ademais, tais organizações comportam a atuação de diferentes atores, muitos com interesses divergentes entre si, e estão submetidas a variados tipos de pressões do meio em que se inserem, entre elas, a política, econômica e cultural.

Portanto, gerir uma organização de saúde - desde um serviço até um sistema - não é tarefa simples. O desempenho da organização não depende exclusivamente da ação dos seus dirigentes, mas é resultado da conjunção de uma série extensa de fatores.

No entanto, ainda que os dirigentes tenham um controle apenas relativo do funcionamento das organizações de saúde, seu papel não deve ser menosprezado. De fato, os gestores intervêm o tempo todo na condução das organizações, e essas intervenções, via de regra, têm conseqüências, sejam elas positivas ou negativas.

Para que as conseqüências sejam as desejáveis ou contribuam para o bom desempenho das organizações, é importante que os dirigentes tomem as decisões adequadas. Dada a complexidade das organizações, tomar decisões irrefletidas ou baseadas apenas no senso comum é um risco que os gestores da saúde não devem correr.

Para decidir conscienciosamente, os dirigentes precisam de informações válidas, confiáveis e atualizadas; de quadros de referência ou modelos analíticos que lhes ajudem a articular o conjunto das informações disponíveis de forma a ter uma compreensão suficientemente ampla e próxima da realidade organizacional.

Na prática da gestão, todo tipo de informação é levado em consideração, assim como os quadros de referência mais utilizados são tácitos - construídos basicamente a partir da experiência de vida do dirigente. Não se espera nem se recomenda que os conhecimentos tácitos deixem de ser mobilizados na gestão da saúde. Ao contrário, sabe-se que a intuição e as emoções têm lugares relevantes no processo de tomada de decisões, freqüentemente contribuindo para que a alternativa mais ajustada seja a escolhida.

Contudo, há uma fonte de informações válidas e de quadros de referência fecundos, que é ciência, cuja importância não pode ser menosprezada. $\mathrm{O}$ conhecimento científico, diferentemente dos outros tipos de conhecimento, tem seu processo de produção submetido ao escrutínio de uma coletividade institucionalizada de profissionais. Somente após passar com sucesso por mecanismos de validação estabelecidos pela comunidade acadêmica, os resultados da pesquisa científica são reconhecidos e aceitos.

Mesmo que se possam apontar limitações ao processo científico de produção de conhecimento, não se pode negar que se trata, entre todos, do processo mais rigoroso e mais eficaz em termos de consistência dos resultados alcançados. Além disso, e por diferentes razões, entre elas a sua efetividade, é o modo de produção de conhecimento de maior impacto na vida das pessoas e das sociedades.

Não se justifica, portanto, que os gestores e os profissionais de saúde não utilizem, ao máximo, o conhecimento científico nas suas atividades específicas. Com ele, podem ter mais informações confiáveis e melhores quadros de referências para tomarem decisões mais apropriadas e, assim, contribuírem mais efetivamente para melhorar o desempenho das suas organizações.

No entanto o Departamento de Ciência e Tecnologia (Decit) reconhece que a utilização do conhecimento científico não é um processo simples, ele necessita ser realizado em várias etapas e em ações paralelas. Para estimular todo esse trabalho, a Coordenação-Geral de Gestão do Conhecimento vem apostando na divulgação 
dos resultados de pesquisa como estratégia de aproximação entre gestão e academia. A estratégia central de estímulo à utilização dos resultados de pesquisa na gestão adotada pelo Decit é a aproximação continuada entre pesquisadores e gestores, em um contexto que promove o debate franco entre esses atores e o acesso à informação por canais e linguagens adequadas.

O conhecimento disponível tem sido traduzido em linguagem não especializada e amplamente veiculado para ter sua acessibilidade aumentada. Já foram produzidos 12 boletins informativos com os principais resultados de cerca de 240 pesquisas concluídas. Esses boletins são enviados a gestores da saúde, da ciência e tecnologia e representantes da comunidade acadêmica.

Além disso, o Decit vem trabalhando para ampliar e adaptar o processo de divulgação do conhecimento às diferentes realidades do Sistema Único de Saúde. Prova disso é a participação dos gestores das três esferas do SUS na definição das prioridades de pesquisas e nos seminários de avaliação, realizados com o intuito de facilitar a incorporação do conhecimento gerado.

Outra ação importante, realizada em 2007, foi a realização do evento "Pesquisa para Saúde: desenvolvimento e inovação para o SUS”, em Brasília. Foi um momento de ricos debates sobre a situação atual e as perspectivas da ciência, tecnologia e inovação em saúde no Brasil. Antes do evento, foram realizados encontros de redes, oficinas de avaliação de resultados de pesquisa, um seminário internacional de avaliação de tecnologias em saúde e um seminário sobre disseminação de informações científicas. A discussão sobre a disseminação científica envolveu representantes da revista Ciência Hoje On-line, do Portal Scidev.net, do Canal Saúde/Fiocruz, entre outros.

Destaca-se também a cooperação com instituições como o Conselho Nacional de Secretarios de Saude, o Conselho Nacional de Secretarias Municipais de Saúde, o Centro Latino-Americano e do Caribe de Informação em Ciências da Saúde (BIREME) e a Fiocruz, que tem sido de grande importância para aproximar os gestores da informação científica.

Além disso, a Secretaria de Ciência, Tecnologia e Insumos Estratégicos participa de projetos internacionais de disseminação científica, com destaque para o Evidence-Informed Policy Network (EVIPnet), rede coordenada pela OMS que propõe estratégias para estimular a cultura de utilização de evidências científicas entre os gestores.

Finalmente, apostando na máxima disseminação do conhecimento científico como forma de favorecer a sua utilização na gestão da saúde e conhecendo a diversidade do público a ser atingido, o Decit tem preferido diversificar as ferramentas e os canais adotados. Essa diversificação reflete a certeza de que nenhuma ação, por si só, é capaz de incentivar a utilização do conhecimento no SUS, o que pode, sim, ser alcançado por um conjunto de ações que tenham o mesmo objetivo. A intenção é sempre envolver o maior número de gestores e demais atores que possam contribuir nesse processo. 